DOI: https://doi.org/10.24127/ajpm.v10i1.3357

\title{
PENGEMBANGAN REALQU UNTUK MEMAKSIMALKAN KEMAMPUAN PEMBUKTIAN MATEMATIS BERDASARKAN ADVERSITY QUOTIENT
}

\author{
Era Dewi Kartika ${ }^{*}$, Dyah Ayu Sulistyaning Cipta ${ }^{2}$, Laila Nur Rohmah ${ }^{3}$ \\ 1,2,3 IKIP Budi Utomo, Malang, Indonesia \\ * Jl Citandui no 46, 65122, Malang, Indonesia. \\ E-mail: $\quad$ erfolgera@gmail.com ${ }^{1 *}$ \\ dyahayu.esce@gmail.com $^{2)}$ \\ lailanurrohmah46@gmail.com $^{3)}$
}

Received 05 December 2020; Received in revised form 12 March 2021; Accepted 19 April 2021

\begin{abstract}
Abstrak
Pandemi Covid-19 yang berimbas pada diterapkannya pembelajaran dalam jaringan mengharuskan pengajar untuk menemukan metode dan strategi pembelajaran yang tepat. Pada penelitian ini menggunakan RealQu, sebuah aplikasi yang dibuat dengan menggunakan Figma dan Android Studio. Dengan menggunakan RealQu, pembelajaran Analisis Real yang dijalankan diharapkan mampu memaksimalkan kemampuan pembuktian matematis siswa berdasarkan adversity quotient. Metode penelitian yang digunakan adalah penelitian pengembangan yang menghasilkan sebuah produk bernama RealQu yang dapat diinstal di ponsel berbasis android. Instrumen penelitian untuk mengetahui kemampuan matematis mahasiswa dilakukan dengan menggunakan kuesioner adversity quotient yang telah dimodivikasi. Hasil penelitian menunjukkan bahwa kemampuan pembuktian matematis berdasarkan adversity quotient sebelum penerapan media pembelajaran RealQu yang dilakukan kepada 20 mahasiswa memperoleh hasil 3 di antaranya berada pada level quitter, 12 berada pada level camper, dan 5 pada level climber. Sedangkan setelah penerapan, terdapat 1 mahasiswa pada level quitter, 7 mahasiswa pada level camper, dan sisanya 12 mahasiswa pada level climber.
\end{abstract}

Kata kunci: Adversity quotient, analisis real, pembuktian matematis

\begin{abstract}
The Covid-19 pandemic, which has an impact on the application of online learning, requires teachers to find the right learning methods and strategies. In this study used RealQu, an application created using Figma and Android Studio. By using RealQu, the Real Analysis learning that is carried out is expected to be able to maximize students' mathematical proof abilities based on the adversity quotient. The research method used is development research which produces a product called RealQu which can be installed on Android-based phones. The research instrument to determine students' mathematical abilities was carried out using a modified adversity quotient questionnaire. The results showed that the ability of mathematical proof based on the adversity quotient before the application of RealQu learning media which was carried out on 20 students obtained results that 3 of them were at the quitter level, 12 were at the camper level, and 5 at the climber level. Meanwhile, after implementation, there were 1 student at the quitter level, 7 students at the camper level, and the remaining 12 students at the climber level.
\end{abstract}

Keywords: Adversity quotient, real analysis, mathematical proof

This is an open access article under the Creative Commons Attribution 4.0 International License

\section{PENDAHULUAN}

Pandemi Covid-19 yang mewabah dan melanda negeri berimbas pada pelaksanaan kegiatan belajar mengajar. Pun demikian dengan Program Studi Pendidikan Matematika IKIP Budi
Utomo. Pembelajaran dalam jaringan menjadi keharusan demi menekan laju penyebaran Covid-19.

Pembelajaran Matematika yang sering membutuhkan penjelasan langsung dengan keterlibatan tatap 
muka, menjadi tantangan tersendiri kala kondisi mengharuskan tidak bisa demikian. Berbagai strategi dan metode pembelajaran pun dibuat demi dapat terlaksanakanya kegiatan belajar mengajar.

Matematika merupakan suatu ilmu yang erat menggunakan logika dan nalar dalam meyakini suatu kebenaran. Untuk itu, selalu diperlukan suatu bukti agar pernyataan dapat diyakini benar. Pembuktian dalam matematika dikenal dengan istilah pembuktian matematis. Pembuktian matematis dilakukan untuk menvalidasi kebenaran suatu pernyataan dengan membuat sekumpulan argumen yang benar dan terkait secara logis menurut aturan inferensi (Kartini, 2015). Pembuktian matematis merupakan sebuah proses yang mencakup argumen dan rangkaian pemikiran matematis (Firmasari \& Sulaiman, 2019).

Dalam melakukan pembuktian matematis, tentu diperlukan suatu kecerdasan untuk menyelesaikannya. Kecerdasan individu dalam menghadapi kesulitan dan bertahan dari kesulitan disebut sebagai Adversity Quotient (Nurhayati \& Fajriyanti, 2015). Dengan demikian, maka semakin tinggi adversity quotient yang dimiliki seseorang, maka semakin tinggi pula kemampuannya dalam melakukan pembuktian matematis.

Kondisi di lapangan, dengan keadaan pembelajaran dalam jaringan, berdampak pada enggannya mahasiswa untuk belajar lebih mendalam. Padahal, rendahnya rasa ingin tahu siswa juga mempengaruhi dalam proses pembelajaran (Mubarok, Pujiastuti, \& Suparsih, 2018). Untuk itu, diperlukan suatu metode dan strategi khusus agar mahasiswa dapat kembali tekun dalam mempelajari matematika. Kegiatan pembelajaran dengan menggunakan media menjadi salah satu solusinya.
Media pembelajaran yang dipilih adalah RealQu, sebuah aplikasi berbasis android yang diciptakan untuk memaksimalkan kemampuan dalam pembuktian matematis berdasarkan adversity quotient.

Media belajar smartphone atau android sangat berpengaruh dalam proses belajar mengajar di era pandemi dan merupakan media yang efektif dalam pembelajaran jarak jauh (Maknuni, 2020). Media berbasis android juga layak diimplementasikan dalam pembelajaran pada saat pandemi covid-19 (Ramdani, 2020). Penggunaan aplikasi pembelajaran online berbasis android menjadi motivasi mahasiswa dan membantu dalam belajar pada masa pandemi corona (Wilson, 2020). Oleh karena itu memang diperlukan media pembelajaran berupa aplikasi berbasis android dalam masa pandemi. Materi bilangan real juga belum pernah disampaikan dalam pembelajaran menggunakan media berbasis android. Hal ini tentu saja menjadi tantangan untuk dosen dalam menyampaikan materi dengan media yang terbarukan. Materi yang dipilih juga membutuhkan ketangguhan mahasiswa untuk memahami serta menyelesaikan soalsoal latihan, sehingga adversity quotient akan sangat diperlukan. Sejauh ini belum ada pengembangan media pembelajaran android berbasis adversity quotient yang menyajikan materi bilangan real. Tujuan dari penelitian ini adalah mengembangkan media untuk memaksimalkan kemampuan pembuktian matematis berdasarkan adversity quotient.

\section{METODE PENELITIAN}

Metode yang digunakan dalam penelitian ini adalah penelitian pengembangan (research and development) yang diadaptasi dari 
(Sugiyono, 2016). Model desain instruksional ADDIE pada penelitian ini meliputi tahap analisis (analyze), desain (design), pengembangan (develop), implementasi (implement) dan evaluasi (evaluate).

Pada tahapan analyze, peneliti melakukan tes adversity quotient kepada mahasiswa program studi Pendidikan Matematika yang menempuh mata kuliah Analisis Real dengan pembelajaran yang dilakukan secara daring. Instrumen yang digunakan dalam tahapan penelitian ini adalah dengan menggunakan kuesioner Adversity Quotient yang telah dimodivikasi.

Analisis pengolahan data dari hasil angket tersebut kemudian menggunakan penskoran seperti pada Tabel 1 .

Tabel 1. Pedoman penskoran angket adversity quotient dengan pernyataan positif

\begin{tabular}{cc}
\hline Respon Mahasiswa & Skor \\
\hline Sering Sekali & 5 \\
\hline Sering & 4 \\
\hline Kadang-kadang & 3 \\
\hline Jarang & 2 \\
\hline Jarang Sekali & 1 \\
\hline
\end{tabular}

Tabel 2. Pedoman penskoran angket adversity quotient dengan pernyataan negative.

\begin{tabular}{cc}
\hline Respon Mahasiswa & Skor \\
\hline Sering Sekali & 1 \\
\hline Sering & 2 \\
\hline Kadang-kadang & 3 \\
\hline Jarang & 4 \\
\hline Jarang Sekali & 5 \\
\hline
\end{tabular}

Berikutnya untuk mengukur tingkat Adversity Quotient mahasiswa, maka digunakan rumus (1):

$$
P=\frac{X}{Y} \times 100
$$

Keterangan:

$\mathrm{P}=$ Tingkat Adversity Quotient

$\mathrm{X}=$ Skor total yang diperoleh

$\mathrm{Y}=$ Skor maksimal

Skor tersebut kemudian dikategorikan dalam kategori tinggi, sedang, dan rendah. Kategori ini kemudian dikonversi dalam berdasarkan standar deviasi berikut.

Tabel 3. Konversi skor angket

\begin{tabular}{cc}
\hline Interval & Kategori \\
\hline$p>x+1,5 \cdot S D$ & Tinggi \\
\hline$x \leq P \leq x+1,5 \cdot S D$ & Sedang \\
\hline$P<x$ & Rendah \\
\hline
\end{tabular}

Selanjutnya, untuk memaksimalkan kemampuan pembuktian matematis mahasiswa, maka ditetapkan untuk membuat media pembelajaran RealQu.

Tahap design dilakukan dengan dengan perancangan RealQu, yaitu menentukan software yang akan digunakan, serta membuat kerangka desain dari media pembelajaran yang akan dibuat.

Pada tahap develop, peneliti telah memutuskan untuk menggunakan aplikasi Figma dan Android Studio dalam proses pembuatan RealQu. Peneliti kemudian membuat aplikasi tersebut berdasarkan rancangan yang telah dibuat pada tahap sebelumnya.

Tahap implement dilakukan dengan validasi RealQu yang telah selesai dikerjakan kepada dua validator ahli di bidangnya, yaitu ahli media dan ahli materi. Pada validasi yang pertama terdapat beberapa hal yang harus direvisi, di antaranya adalah muatanmuatan pembuktian yang diberikan terlalu cepat sehingga kurang memaksimalkan kemampuan pem- 
buktian matematis mahasiswa berdasarkan adversity quotient. Peneliti kemudian memperbaiki RealQu dan kembali divalidasi hingga dikatakan layak untuk dilakukan uji coba kepada 20 mahasiswa yang sedang menempuh mata kuliah Analisis Variabel Real di Program Studi Pendidikan Matematika IKIP Budi Utomo.

Pada tahap evaluate, dianalisis hasil kerja mahasiswa dalam pembelajaran dengan menggunakan RealQu sesuai dalam lembar observasi. Hal ini kemudian dilanjutkan dengan mengidentifikasi peningkatan kemampuan pembuktian matematis yang diamati berdasarkan hasil angket adversity quotient. Seluruh rangkaian penelitian ini dilakukan pada April hingga September 2020.

\section{HASIL DAN PEMBAHASAN}

Pada penelitian terdahulu, peneitian yang dilakukan oleh (Faris, Ulfa, \& Praherdhiono, 2019) dengan judul Teknologi Pembelajaran Matematika Pembuktian Teorema Phytagoras Berbasis Visual memaparkan bahwa dengan menerapkan program GeoGebra sebagai media dalam proses pembelajaran matematika akan melatih keterampilan mereka yang dapat meningkatkan pemahaman yang mereka temukan sendiri. (Junizon, 2019) dalam penelitian berjudul Pengaruh Model Pembelajaran Extended Triad Level ++ Terhadap Kemampuan Pembuktian Teorema Pada Analisis Real Di Universitas Muhammadiyah Bengkulu menghasilkan bahwa kemampuan pembuktian teorema yang diajar melalui model pembelajaran Extended Triad Level ++ lebih baik dari pada mahasiswa yang diajar menggunakan model konvensional. Melihat keberhasilan pembelajaran yang telah dilakukan sebelumnya dengan melibatkan teknologi, maka dalam penelitian ini dikembangkan pembelajaran dengan menggunakan media serupa. Sebelumnya, belum ada penelitian yang mengulas tentang pengembangan media sejenis RealQu, juga belum ada penelitian media tersebut terhadap kaitannya dengan kemampuan pembuktian matematis berdasarkan adversity quotient. Pada (Kartika \& Yazidah, 2019) hanya diungkapkan tentang analisis kemampuan pembuktian matematis pada matakuliah Analisis Real berdasarkan adversity quotient, tanpa memanfaatkan media apapun.

Pada penelitian ini, hasil penelitian yang didapatkan adalah kemampuan pembuktian matematis berdasarkan adversity quotient sebelum penerapan media pembelajaran RealQu yang dilakukan kepada 20 mahasiswa memperoleh hasil 3 di antaranya berada pada level quitter, 12 berada pada level camper, dan 5 pada level climber.

Adversity quotient dipandang sebagai kecerdasan individu yang mampu meramalkan kemampuan dalam bertahan menghadapi kesulitan serta cara mengatasinya, kesanggupan seseorang bertahan dalam menjalani hidup (Supardi, 2013). Pada dasarnya, kecerdasan individu setiap orang berbeda-beda, tingkat kemampuan inilah yang berdampak pada kemampuan seseorang dalam kesanggupannya menjalani kehidupan ini.

Dosen seyogyanya mengetahui adversity quotient mahasiswa sebelum pembelajaran. Dengan demikian, maka dapat dilanjutkan dengan membuat program pengembangan adversity quotient sehingga keberhasilan siswa dalam belajar dapat dioptimalkan (Rukmana, Hasbi, \& Paloloang, 2016).

(Hodiyanto \& Susianty, 2018) menyatakan bahwa kemampuan pem- 
buktian matematis perlu ditingkatkan karena kemampuan pembuktian sangat penting untuk pembelajaran matematika yang mendalam. Selain itu, kemahiran dalam pembuktian dapat meningkatkan kemampuan matematis mereka lebih luas, dan ditemukannya kesulitan yang dihadapi oleh banyak siswa dan mahasiswa dalam pembuktian matematika.

$$
\text { Langkah-langkah pembuatan }
$$
media pembelajaran RealQu yang ditujukan untuk meningkatkan kemampuan pembuktian matematis mahasiswa diawali dengan membuat wireframe aplikasi (low-fidelity \& high-fidelity) menggunakan figma seperti Gambar 1.

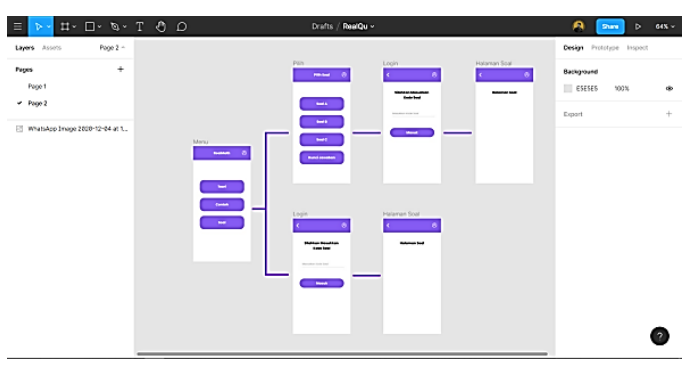

Gambar 1. Ruang kerja Figma

Berikutnya, setelah seluruh wireframe berhasil dibuat, maka akan dilanjutkan dengan pembuatan prototype, lalu mengimplementasikannya kedalam kode menggunakan android studio. Pembuatan wireframe membutuhkan waktu 2 minggu, sedangkan untuk membuat kode membutuhkan waktu 1 minggu.

Selanjutnya, pada tahap akhir dalam pembuatan RealQu adalah dengan merilis hasil kode ke format apk agar bisa diinstal langsung pada device android. Gambar 3 adalah tampilan dari RealQu yang telah selesai dibuat. RealQu dapat diselesaikan dalam waktu satu bulan.

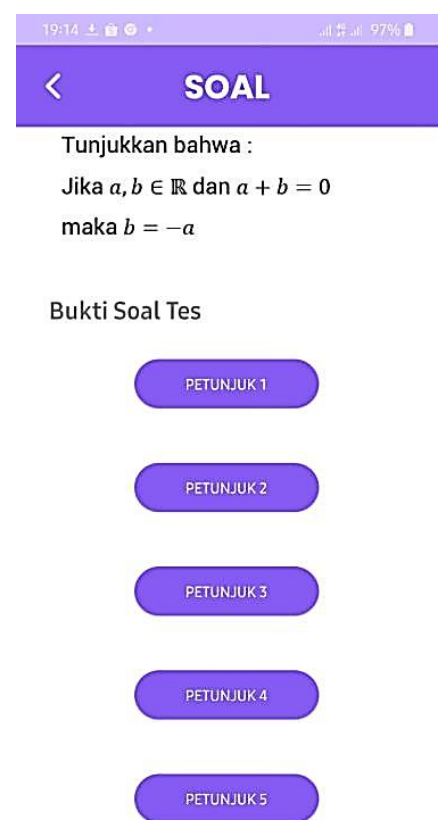

$=$

Gambar 3

Contoh tampilan RealQu

Pada tahap implement, terdapat dua ahli yang menjadi validator, yaitu ahli media dan ahli materi. Setelah melalui validasi yang pertama dan peneliti melakukan revisi sesuai permintaan validator, maka keduanya memberikan nilai valid dan layak dengan rata-rata 3,61 dengan nilai maksimal 4.

Selanjutnya, setelah media pembelajaran RealQu tersebut divalidasi dan dinyatakan layak untuk diujicobakan, maka 20 mahasiswa yang telah diberikan tes adversity quotient diminta untuk mendownload aplikasi tersebut di ponsel android masingmasing. Pembelajaran dengan menggunakan RealQu diterapkan dalam empat kali tatap muka. Hasilnya, 3 mahasiswa yang berada di level quitter, yang sebelumnya hanya mampu menuliskan soal, tetapi tidak memahami maksud dari soal, setelah penerapan RealQu, satu dari ketiganya dapat menuliskan apa yang diketahui dari 
soal, tetapi tidak jelas dan tidak lengkap. Sedangkan dua di antaranya, sudah bisa menuliskan dengan jelas dan lengkap. Hanya saja, keduanya masih salah dalam menyelesaikan pembuktiannya. (Suhartono, 2017) menyebutkan bahwa mahasiswa dalam kategori quitter adalah mereka yang mudah putus ada dan keluar dari masalah. Dalam hal ini, quitter hanya mampu menulis ulang soal tanpa bisa melanjutkan penyelesaian.

Mahasiswa dengan level camper terdapat 12 orang. Hasil yang diperoleh dari menyelesaikan latihan soal setelah RealQu diterapkan adalah semuanya mampu menuliskan soal dan apa yang diketahui dengan definisi yang baik dan jelas, tetapi masih terdapat penulisan lambang yang salah. Hanya ada 5 mahasiswa saja yang mampu menyelesaikan soal latihan dengan tahapan yang benar hingga teorema terbukti, sedangkan sisanya masih terdapat tahapan yang salah atau tidak mampu menyelesaikan hingga tahap akhir pembuktian. Mahasiswa camper menurut (Darojat \& Kartono, 2016) mampu merencanakan pemecahan masalah dengan tepat dan dapat menentukan rumus apa saja yang akan digunakan untuk menyelesaikan soal dengan tepat. Mahasiswa tersebut terkadang masih salah dalam menuliskan simbol matematika dan pekerjaannya belum terselesaikan hingga akhir.

Untuk tipe yang terakhir, climber adalah mahasiswa yang umumnya tidak mengenal istilah menyerah dalam menghadapi kesulitan, mereka selalu mengupayakan solusi dan sangat mampu bertahan dalam menghadapi kesulitan yang berat (Khumairoh, Amin , \& Wijayanti, 2020). Dalam hal ini, lima mahasiswa tersebut dapat mengerjakan hingga selesai, tetapi masih ada teorema yang salah. Belum sempurna.

RealQu diberikan selama masa pandemi. Mahasiswa di rumah diminta untuk menginstal RealQu pada ponsel masing-masing. Uji coba RealQu pada pembelajaran Analisis Real dilakukan dengan bantuan aplikasi media tersebut. Selaras dengan penelitian (Mustaqim, 2020), inovasi pembelajaran dengan menggunakan media online akan membantu mahasiswa dalam menjalani pembelajaran daring selama pandemi covid-19. Pun demikian dengan RealQu, melalui aplikasi tersebut, pembelajaran analisis real menjadi lebih mudah dijalankan.

Dalam keadaan normal, menurut (Sudarman, 2011), mahasiswa quitter cenderung menghindar ketika akan diberikan soal dan ketika akan diwawancarai. Pun demikian dengan penelitian ini. Ada beberapa mahasiswa quitter yang enggan mengerjakan angket.

Setelah proses pembelajaran matematika menggunakan media RealQu, mahasiswa dapat memaksimalkan kemampuan pembuktian matematisnya yang terlihat dengan kenaikan nilai adversity quotient. Aspek kepraktisan dilihat dari angket respon siswa yang berada pada kriteria baik sebesar 3,72 dengan nilai maksimal 4 . Sedangkan keefektifan dilihat dari penyelesaian soal latihan mahasiswa yang meningkat pada akhir tindakan, Hasil penelitian menunjukkan bahwa kemampuan pembuktian matematis berdasarkan adversity quotient sebelum penerapan media pembelajaran RealQu yang dilakukan kepada 20 mahasiswa memperoleh hasil 3 di antaranya berada pada level quitter, 12 berada pada level camper, dan 5 pada level climber. Sedangkan setelah penerapan, terdapat 1 mahasiswa pada level quitter, 7 
mahasiswa pada level camper, dan sisanya 12 mahasiswa pada level climber.

Setelah melalui uji coba penerapan RealQu tersebut, dengan melihat adanya peningkatan kemampuan pembuktian matematis siswa, maka diputuskan bahwa pada semester ganjil 2020/2021 yang masih dilakukan pembelajaran dalam jaringan, Matakuliah Analisis Real diberikan dengan menggunakan bantuan RealQu.

RealQu memiliki kelebihan bahwa ia lebih baik dalam meningkatkan kemampuan pembuktian matematis mahasiswa, dibandingkan dengan hanya menggunakan buku text dan pembelajaran via zoom meeting. Kendala-kendala kesulitan jaringan yang biasa dialami siswa dalam pelaksanaan pembelajaran dengan menggunakan zoom dapat teratasi. Melalui RealQu, kini mahasiswa dapat menggunakannya secara fleksibel dan tidak memerlukan kuota berlebih. Hanya saja, kekurangan dari media ini adalah bahwa tidak semua ponsel kompetibel untuk menginstal RealQu. RealQu hanya bisa support pada ponsel berbasis android saja.

\section{KESIMPULAN DAN SARAN}

Berdasarkan hasil penelitian yang telah dibahas di muka, maka dapat disimpulkan bahwa pengembangan media pembelajaran RealQu dapat memaksimalkan kemampuan pembuktian matematis mahasiswa berdasarkan adversity quotient pada matakuliah Analisis Variabel Real.

Pada penelitian selanjutnya, diharapkan dapat mengembangkan aplikasi ini dengan membuat figma yang lebih bagus lagi, serta dapat dikembangkan pada mata kuliah lain yang banyak menggunakan pembuktian matematis.

\section{DAFTAR PUSTAKA}

Darojat, L., \& Kartono. (2016). Kemampuan Pemecahan Masalah Siswa dalam Menyelesaikan Soal Open Ended Berdasarkan AQ dengan Learning Cycle 7e. Unnes Journal of Mathematics Education Research, 6(1), 8 - 14.

Faris, M. N., Ulfa, S., \& Praherdhiono, H. (2019). Teknologi Pembelajaran Matematika Pembuktian Teorema Phytagoras Berbasis Visual. Jinotep: Jurnal Inovasi Teknologi Pembelajaran, 6(1), 8 - 14.

Firmasari, S., \& Sulaiman, H. (2019). Kemampuan Pembuktian Matematis Mahasiswa Menggunakan Induksi Matematika. Journal of Medives, 3(1), 1 - 9.

Hodiyanto, \& Susianty, U. D. (2018). Peningkatan Kemampuan Pembuktian Matematis Melalui Model Pembelajaran Problem Posing. MaPan: Jurnal Matematika dan Pembelajaran, 6(1), 130139.

Junizon, M. (2019). Pengaruh Model Pembelajaran Extended Triad Level ++ Terhadap Kemampuan Pembuktian Teorema Pada Analisis Real Di Universitas Muhammadiyah Bengkulu. Jurnal Pendidikan Matematika Raflesia, 4(1), 44 - 52.

Kartika, E. D., \& Yazidah, N. I. (2019). Analisis Kemampuan Pembuktian Matematis pada Matakuliah Analisis Real Berdasarkan Adversity Quotient. PRIMA: Jurnal Pendidikan Matematika, 3(2), 152 - 157.

Kartini, E. S. (2015). Analisa Kesulitan Pembuktian Matematis Mahasiswa pada Mata Kuliah 
Analisis Real. SEMIRATA, 3(2), 189 - 199.

Khumairoh, B., Amin , S. M., \& Wijayanti, P. (2020). Penalaran Proporsional Siswa Kelas Menengah dalam Menyelesaikan Masalah Matematika Ditinjau dari Adversity Quotient. PEDAGOGIA: Jurnal Pendidikan, 9(1), 67 - 80.

Maknuni, J. (2020). Pengaruh media Belajar Smartphone Terhadap Belajar Siswa Di Era Pandemi Covid-19. IDEAL: Indonesian Education Administration and Leadership Journal, 2(2), 94 106.

Mubarok, M. S., Pujiastuti, E., \& Suparsih, H. (2018). Meningkatkan Kemampuan Pembuktian Matematis dan Rasa Ingin Tahu Siswa Kelas XI MIPA SMA Negeri 6 Semarang Melalui Model PBL. PRISMA: Prosiding Seminar Nasional Matematika (pp. 677 - 683). Semarang: Universitas Negeri Semarang.

Mustaqim. (2020). Efektivitas Pembelajaran Daring Menggunakan Media Online Selama Pandemi Covid-19 Pada Mata Pelajaran Matematika. Al Asma: Journal of Islamic Education, 2(1), 1 - 12.

Nurhayati, \& Fajriyanti, N. (2015). Pengaruh Adversity Quotient (AQ) dan Motivasi Berprestasi Terhadap Prestasi Belajar Matematika. Jurnal Formatif, 3(1), 72 - 77.
Ramdani, A. (2020). Pengembangan Media Pembelajaran Berbasis Android pada Masa Pandemi Covid-19 untuk Meningkatkan Literasi Sains Peserta Didik. Jurnal Hasil Penelitian dan Kajian Kepustakaan di Bidang Pendidikan, Pengajaran dan Pembelajaran, 6(3), 433 - 440.

Rukmana, I., Hasbi, M., \& Paloloang, B. (2016). Hubungan Adversity Quotient Dengan Hasil Belajar Matematika Siswa Kelas XI SMA Negeri Model Terpadu Madani Palu. Jurnal Elektronik Pendidikan Matematika Tadulako, 3(3), 325 - 333.

Sudarman. (2011). Proses Berpikir Siswa Quitter Pada Sekolah Menengah Pertama Dalam Menyelesaikan Masalah Matematika. Edumatica, 1(2), 15 24.

Sugiyono. (2016). Metode Penelitian Kuantitatif, Kualitatif dan $R \& D$. Bandung: PT Alfabet.

Suhartono. (2017). Adversity Quotient Mahasiswa Pemrogram Skripsi. Jurnal Matematika dan Pembelajaran, 5(2), 209 - 220.

Supardi. (2013). Pengaruh Adversity Qoutient Terhadap Prestasi Belajar Matematika. Jurnal Formatif, 3(1), 15 - 24.

Wilson, A. (2020). Penerapan Metode Pembelajaran Daring (Online) Melalui Aplikasi Berbasis Android Saat Pandemi Global. SAP: Susunan Artikel Pendidikan, 5(1), $66-72$. 